\title{
The Impact of 3D Printing Technology to the Nigerian Manufacturing GDP
}

\author{
Vincent A. Balogun ${ }^{*}$, Omonigho B. Otanocha ${ }^{2 *}$, Akii O. Ibhadode ${ }^{2}$ \\ ${ }^{1}$ Department of Mechanical Engineering, Faculty of Engineering, Edo University, Iyamho, Nigeria \\ ${ }^{2}$ Department of Mechanical Engineering, College of Technology, Federal University of Petroleum Resources, \\ Effurun (FUPRE), Effurun, Nigeria \\ Email: *vin œnt.balogun@edouniversity.edu.ng, *otanocha.omonigho@fupre.edu.ng
}

How to cite this paper: Balogun, V.A., Otanocha, O.B. and Ibhadode, A.O. (2018) The Impact of 3D Printing Technology to the Nigerian Manufacturing GDP. Modern Mechanical Engineering, 8, 140-157. https://doi.org/10.4236/mme.2018.82010

Received: October 5, 2017

Accepted: May 12, 2018

Published: May 15, 2018

Copyright $\odot 2018$ by authors and Scientific Research Publishing Inc. This work is licensed under the Creative Commons Attribution International License (CC BY 4.0).

http://creativecommons.org/licenses/by/4.0/

\begin{abstract}
3D printing can spur manufacturing rebirth in Nigeria and the World in general. There are many areas where 3D printing is creating significant change, particularly in designing and prototyping of new products, in the arts, and in visualizing abstract concepts. This is a step change from conventional manufacturing processes to rapid prototyping and layer manufacturing. This report has defined rapid prototyping, rapid manufacturing and the current technologies available to fabricate $3 \mathrm{D}$ components. In addition to this, it provides a brief overview of the current contributions of the Edo University Iyamho (EUI) in collaboration with the Federal University of Petroleum Resources, to sustain manufacturing research initiatives towards the development of locally fabricated 3D printer and the possible future Additive Manufacturing in $\mathrm{Ni}$ geria. It is anticipated that this work will benefit the Nigerian academic, research institutes, industries, thus, enhance the GDP contribution of the manufacturing sector in Nigeria.
\end{abstract}

\section{Keywords}

Additive Manufacture, 3D Printing, Rapid Prototyping, Nigerian Manufacturing GDP

\section{Introduction}

\section{Additive Manufacturing}

Additive Manufacturing (AM) is a new manufacturing method which builds 3D objects by adding material layer-by-layer to produce the object. These materials could be plastic, metal, concrete or human tissue [1]. Additive manufacturing 
uses three dimensional (3D) printing to transform engineering design files into fully functional and durable objects. Additive Manufacturing (AM) improves the flexibility and convenience of a variety of manufacturing applications and has enormous potential to lower manufacturing costs and reduce time to market [2] [3]. This new manufacturing methods also regards the innovation and the integration of the technologies of designing and manufacturing of products by considering the new concepts of CAD/CAPP/CAM/CIM, Rapid Manufacturing/ Prototyping, Reverse Engineering, Concurrent Engineering, Virtual Engineering, Knowledge Engineering, Quality Engineering, etc. The technology has exploded the transformation of manufacturing companies transitioning from "analogue" to "digital" manufacturing techniques. Rapid prototyping (RP) is a general term that describes a variety of systems that is used to construct three-dimensional physical objects directly from CAD data [4] [5].

$3 \mathrm{D}$ printers are machines that use the principles of additive manufacturing methods by adopting a CAD (Computer Aided Design) model to perform Rapid Prototyping. The 3D printers have the capability to print the CAD data in three dimensions ( $\mathrm{x}, \mathrm{y}$, and $\mathrm{z}$ axes) [6].

$3 \mathrm{D}$ printing technology is currently being adopted in many professional career fields that include engineering and biology as a result of the technological advancement in material science [7] [8] [9]. At present, limited numbers of material is available but research is on-going to incorporate more materials for commercial 3D printing. For example the two widely used materials in Fused Deposition Modelling FDM 3D printing are the Acrylonitrile Butadiene Styrene (ABS) [10] and Poly Lactic Acid (PLA) plastics although more materials options are being produced like rubber, bronze, wood, etc. Until part quality improves, it is unlikely that the technology will be used widespread or in more demanding applications.

There are different types of 3D Printers available globally and they all follow the basic steps in creating objects from computer 3D models layer by layer. It is believed that the technology could greatly benefit the manufacturing industry as a whole, particularly, small to medium sized enterprise (SME). This is because it can fabricate a small number of customised parts faster than conventional manufacturing techniques, significantly reducing the "time to market" and cost.

With natural resources becoming more and more expensive, sustainability is becoming increasingly important to manufacturers in Nigeria. This has led the manufacturers to looking for alternatives and more efficient techniques for the production of their products. As a result, there has been a surge interest in RP and RM technologies globally because they produce almost no waste and are perceived to be more sustainable than material removal manufacturing methods. Interestingly, more materials than ever before are gradually becoming available to fabricate parts and thereby reducing the occurrence of machine/process errors. Hence, RP and RM technologies have enormous potential to reshape modern manufacturing globally and in Nigeria. 


\section{The Contribution of Manufacturing to the GDP}

\subsection{Nigerian Manufacturing GDP}

Additive manufacturing technologies grows globally with approximately $35.2 \%$ in 2013 and valued at 4.3 billion dollars [11]. This growth is attributable to the general increase in manufacturing equipment. This growth trends increases to 7.9 billion dollars in 2016 and it is projected to increase to 12 billion dollars by 2020 [12].

In Nigeria the Bureau of Statistic reported that nominal GDP growth in manufacturing in the Second Quarter of 2016 was recorded at negative 1.02\% (year-on-year), $1.09 \%$ points lower than the $0.07 \%$ recorded in the corresponding period of 2015 [13]. This accounts for the drop in the contributions of steel, mining, etc. In 2010, the manufacturing sector was valued at N3, 578,641.72 million. This represented $6.55 \%$ of the total real GDP in that year. It further grew to N4, 527,445.06 million or 7.79\% of real GDP in 2011 and to N5, 588,821.69 million or $7.79 \%$ of real GDP in 2012. However, growth was highest in 2013, to N7, $233,322.48$ million or $9.03 \%$ of real GDP, a value that had not been recorded in decades as shown in Figure 1 and Figure 2.

In 2013, Nigeria released the results of its GDP rebasing estimates.

This trend reveals that the manufacturing sector continually increases the GDP from 2010 to 2013. Prior to rebasing of the Nigerian GDP, manufacturing included just three activities-Oil Refining, Cement and Other Manufacturing. Now, the other manufacturing activity has been broken down into 11 different activities, bringing the total for the manufacturing sector to 13 as shown in Figure 3.

From Figure 3, it can be observed that the highest contributing sector is the food, beverage and tobacco followed by the textile, apparel and footwear sector. The application of 3D printing in any or all of these sector could spur a rapid growth within the sector and hence an increase in the Nigeria manufacturing GDP contribution.

\subsection{Employment in the Manufacturing Industries}

The majority of those employed in the Nigerian manufacturing sector are Nigerian males. Those It has been reported that in 2010, Nigerian males and females that are engaged account for $78.62 \%(2,264,916$ employees) and 546,805 or $18.98 \%$ respectively. In the same year, those with paid employment are made up of $81.14 \%(1,922,223$ employees) Nigerian males and 391,362 or $16.52 \%$ Nigerian females. It has also been reported that $2.41 \%$ and $0.41 \%$ of non-Nigerian males and females respectively can be classified among those that are engaged within the country for 2010 [14].

In 2011, Nigerian males in employments increased by $4.98 \%$ engaged and $9.01 \%$ in paid employment to reach a net total of 2,377,701 and 2,095,320 engaged and in paid employment respectively as shown in Figure 4. For Nigerian males, the increase in engagement in employment in the manufacturing sector 


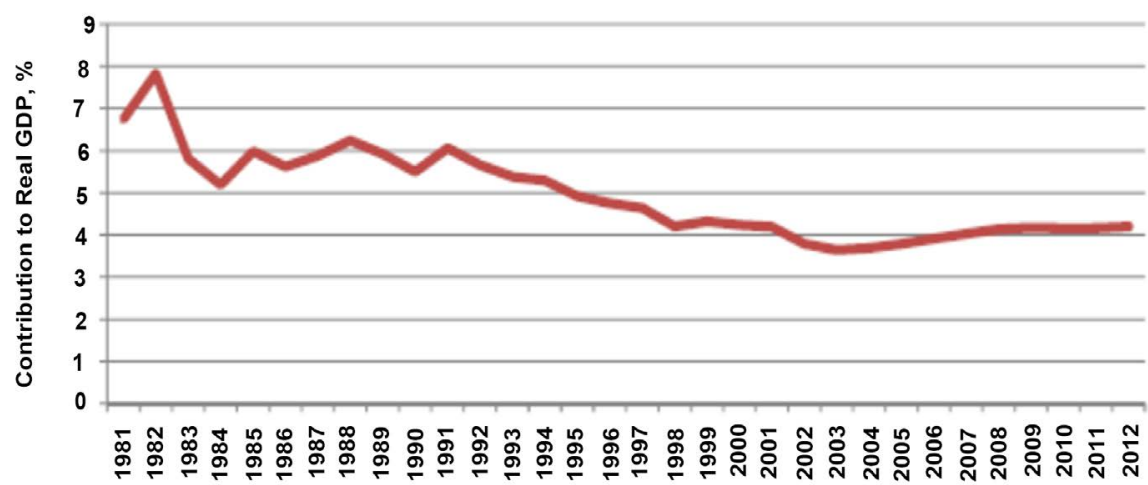

Figure 1. Manufacturing sector contribution to real GDP over time (old series) [13].

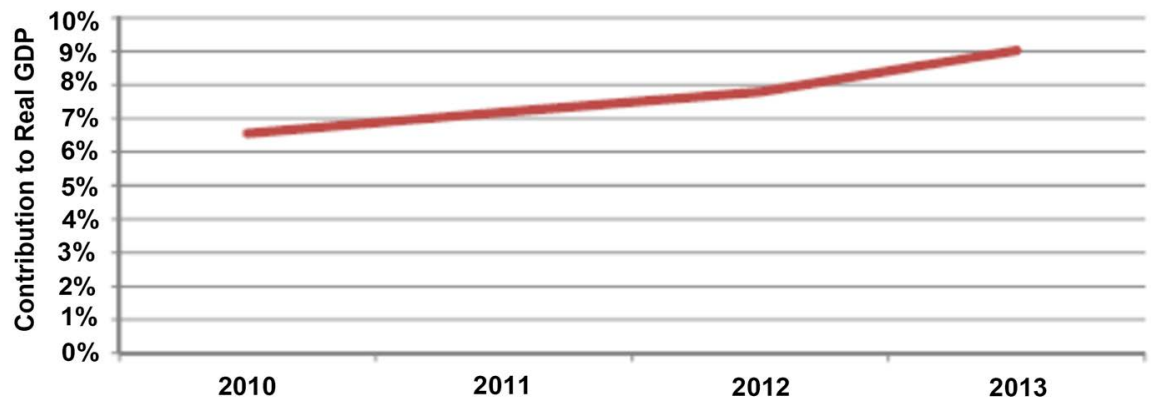

Figure 2. Manufacturing sector contribution to GDP post-rebasing [13].
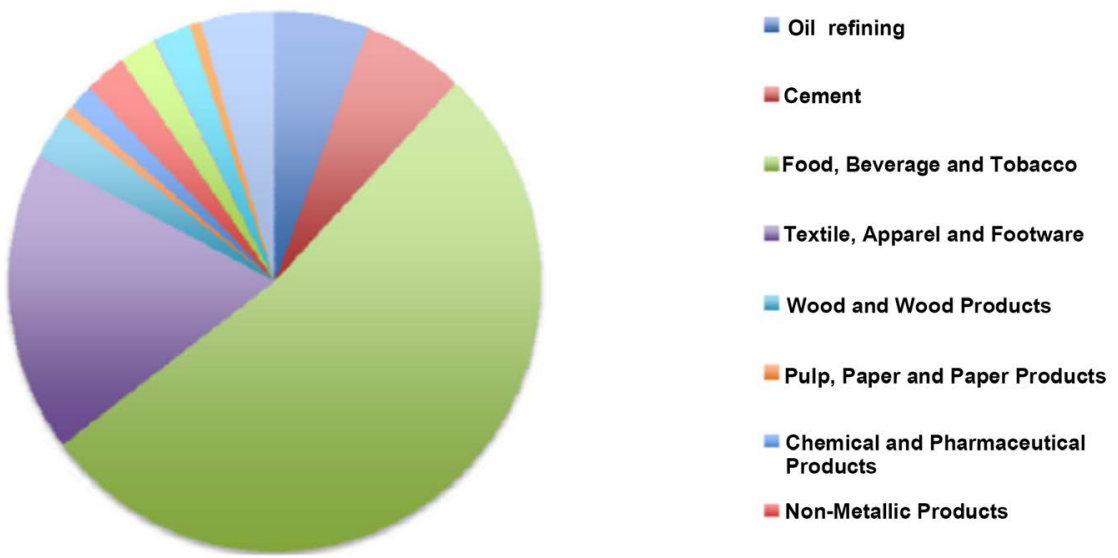

Figure 3. Composition of the Nigerian manufacturing sector in 2013 [13].

continued in 2012, reaching a total of 2,381,435 engaged [14]. From Figure 4, it can be observed that males employment (those engaged or paid) is increasing though at a lower rate. This trend could be enhanced by creating more opportunities through the introduction of a sustainable manufacturing technology.

\subsection{How Connected Is 3D Printing to Manufacturing in Nigeria}

3D Printing otherwise known as Direct Digital Manufacturing; or Additive Manufacturing is a process in which a real physical object is created from a computer $3 \mathrm{D}$ model. This technology is a rapidly evolving technology that is 


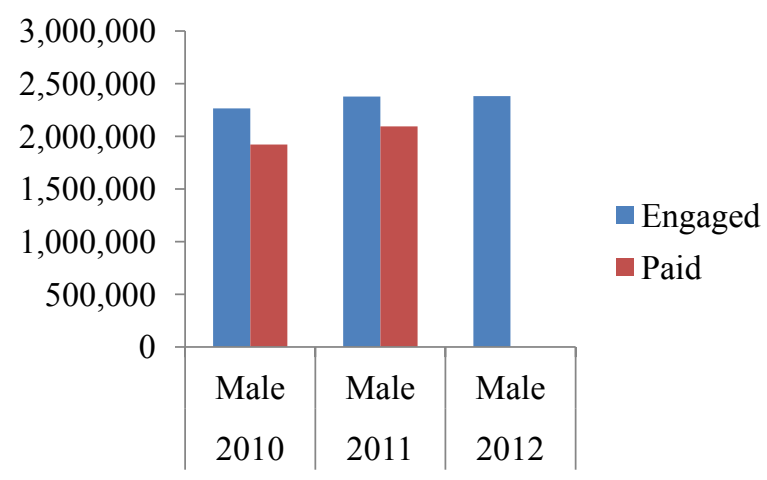

Figure 4. Employment data for Nigerian Males in the manufacturing sector [14].

challenging the status quo in Manufacturing. The technology is widely applicable and linked to many industries in Nigeria.

\section{Applications of 3D Printing Technology in the Nigerian Manufacturing Sector}

$3 \mathrm{D}$ printing technology is now used in prototyping and distributed manufacturing with applications in architecture, construction, industrial design, automotive design, aerospace, military, engineering, etc. It has also become popular in areas such as dental and medical technology, fashion, footwear, jewellery, eyewear, and many more. Interestingly, even food is being printed nowadays [15] [16]. With the addition of 3D digitizers, 3D sensors and 3D scanners, the possibilities are almost endless. Recently, NASA has been testing rocket parts built by $3 \mathrm{D}$ printing and may even use the technology to build habitats in space and on other Worlds. Along with the many useful everyday things that $3 \mathrm{D}$ printers can give us, medical researchers are now using 3D-printed technologies to save human lives [17].

Other available applications in Nigeria could include for example in Engineering; this technology is adopted in iterative designs, robust parts and precision prototyping. This could enhance designs and help engineering teams manage risks and understand the performance implications of their designs. Also, reduced product development cost and time, with improved product quality and durability. It can provide performance insights earlier in the development process, when design changes are less expensive to make. Warranty exposure is reduced by identifying and eliminating potential problems. When properly integrated into product and manufacturing development, 3D printing can enable earlier problem resolution, which can dramatically reduce the costs associated with the product lifecycle. Nigeria and other developing countries can benefit from the rapidly evolving 3D technologies. For example in the development of commercial products, architecture, education, entertainment, household products, jewellery design, medical and toys. The only limit to the fabrication of any design lies in the imaginative capacity of the designer.

Based on the statistics above, the possibility of adapting and integrating the 
3D printing technology into the manufacturing sector could not be overemphasise as it cut across all facet of life. If integrated, the sector could grow exponentially because it will reduce time to market and undue waste of resources due to unnecessary prototypes testing.

\section{Overview of Rapid Prototyping}

$\mathrm{RP}$, or layer manufacturing (LM) techniques, have existed for almost 30 years now. A part is fabricated from a 3-D solid model produced in CAD, using additive processes, generating a solid-free form physical model in layers and therefore reducing the amount of material required to produce the part and reducing the time to market [3] [18]. It shortens the product life cycle [18] [19] [20] significantly because it can produce functional prototypes [21] in a short period of time and can cut costs by up to $70 \%$ and the time to market by $90 \%$ [22]. This is what spurred up the initial interest in the technology [3]. However, as simulation software such as Finite Element Analysis FEA and Computational Fluid Dynamics CFD improves, the necessity for fully functioning prototypes is diminishing. Technological improvements have meant that it is now possible to produce end-use parts.

Figure 5 shows the standard process of RP. A CAD model is uploaded to specialist software. This software discretises or slices the model in the Z-axis direction so that an RP machine can construct a 3-D model in layers without the need of tooling. The information is then processed and uploaded to the machine that begins fabricating the model in layers. Post processing may be required if a support material is used during the fabrication process.

RP technology can be divided into two types of process, non-melting and melting. The determining parameter for classification is the mould material. For example various ranges of materials available include liquids, powders, solids and gas. These are used to produce parts in layers. Initially the technology was only capable of producing non-metallic parts. However developments in materials over the last two decades have enabled RP to produce both metallic and ceramic parts, and more recently composites [24].

\subsection{Types of $3 \mathrm{~d}$ Printing Technology}

At present, there are several types of RP technology available. Some are discussed below:

\subsubsection{Fused Deposition Modelling}

Fused deposition modelling (FDM) was developed by Stratasys Inc. and now growing to become one of the most popular RP processes [10] [20]. The build platform indexes along the z-axis to allow the deposition of build material in layers [24]. All movements are controlled by software that provides a path for the nozzle to follow. A CAD file model is sliced with the software instructing the nozzle to deposit a thin layer of extruded plastic and support for each slice onto the base plate initially. Then the build platform moves down as shown in Figure 6, 


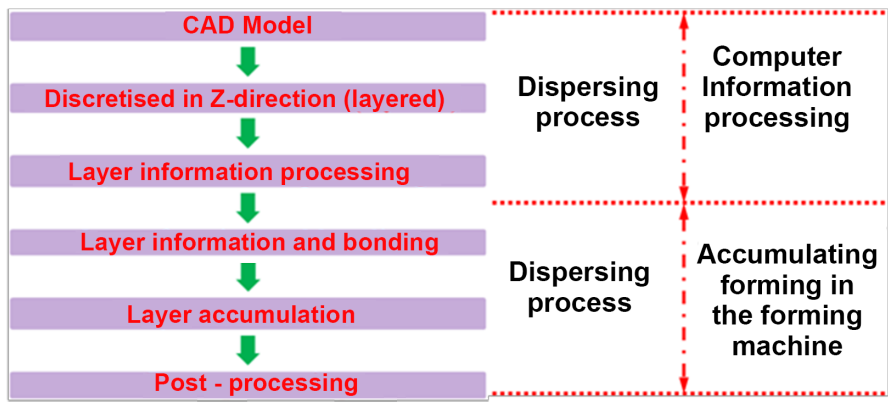

Figure 5. Flow chart of the RP process adapted from [23].

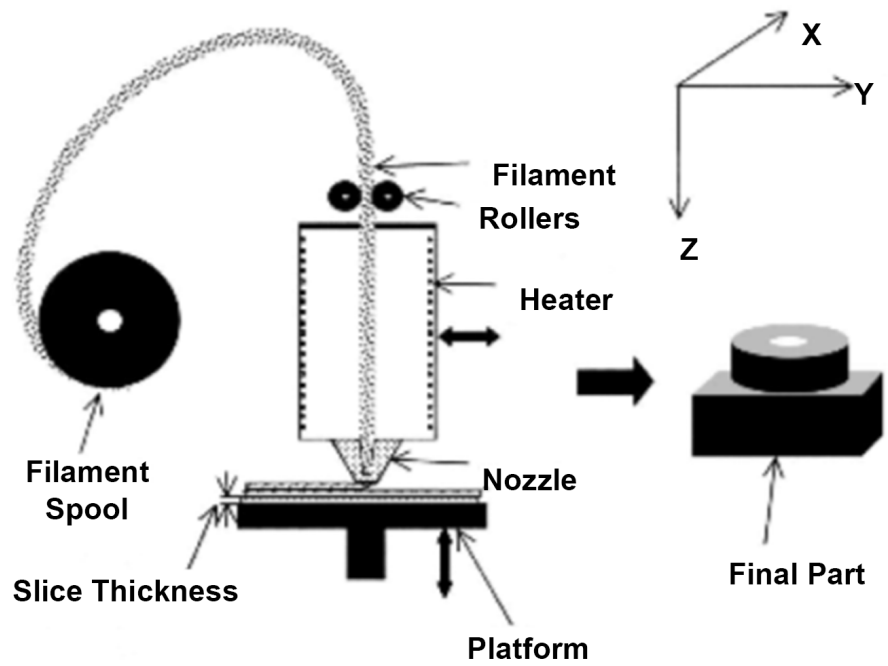

Figure 6. A schematic of the mechanism of operation of a fused deposition modelling machine adapted from [24].

and the deposition process is repeated for the next slice. If a support material is used, as often the case, the part has to be post processed to remove any support material. This is done in a heated bath of detergent.

\subsubsection{Stereo-Lithography}

Stereolithography (SLA) emerged in the 1980s. Stereo-lithography (SLA) is a photo polymerization process for RP and it was the first RP technique to be commercially developed [10]. The SLA process allows for the fabrication of solid plastic 3-D parts from CAD data. This process is repeated until the model is complete as shown in Figure 7.

Improvements such as new resins, improved slicing software and the use of Ultra Violet (UV) lasers have increased the accuracy of SLA, however the process is still not seen to be accurate enough to be used to produce end-use components [25]. Also, SLA is a slow RP process, taking longer time to fabricate parts when compared with other RP technologies.

\subsubsection{Selective Laser Sintering}

Selective laser sintering (SLS) was initially designed by the University of Texas in Austin and the technology was later commercialised by the DTM Corporation in 


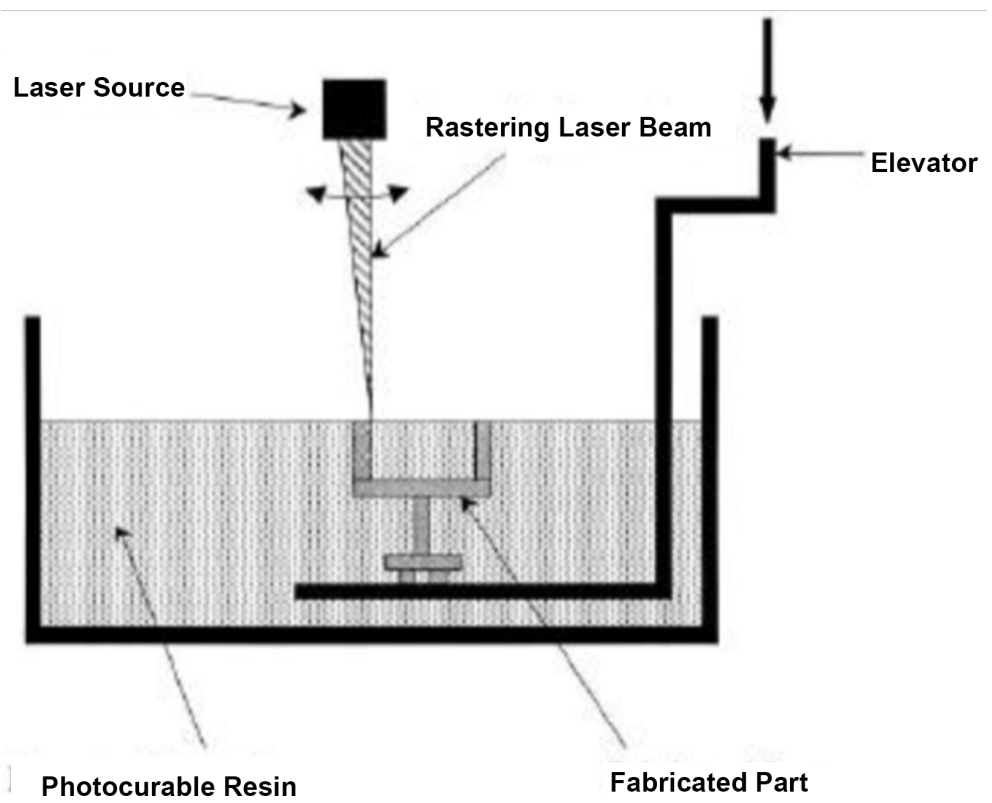

Figure 7. Schematic diagram showing the operation of a typical stereolithography apparatus adapted from [24].

1987 [24]. The process is a combination of both 3D Printing and SLA as it fuses a dry powder together using a laser beam to create a model [21]. The loose powders inside the powder bed always act as a support material for any overhangs or undercuts. This means that very complex geometries can be built with the SLS technology as shown in Figure 8.

\subsubsection{Electron Beam Melting (EBM)}

Electron Beam Melting is extremely similar to Selective Laser Melting SLM; where an electron beam is incorporated to melt the powder as shown in Figure 9. Unlike models produced by SLM, EBM models are fully dense, void-free, and extremely strong.

Other RM technologies are as enumerated in Table 1.

\subsection{General Basic Procedures Involved in 3D Printing}

Preliminary Manufacture of 3D Printer: Purchase or Design with Local Material?

The 3D printer is a Mechatronics device that involves the synergy between the hardware and software components for higher accuracy and precision manufacture of sustainable products. Figure 10 shows the general operation of an extrusion deposition of 3D printing technology.

In extrusion deposition, Fused Deposition technique is used. In this process, a plastic or wax material is extruded through a nozzle that traces the part cross-sectional geometry layer by layer based on the path trajectory from the CAD file in the form of G-codes. The build material is usually supplied in filament form, but some setups utilize plastic pellets fed from a hopper instead. The nozzle contains resistive heaters that keep the plastic at a temperature just above 


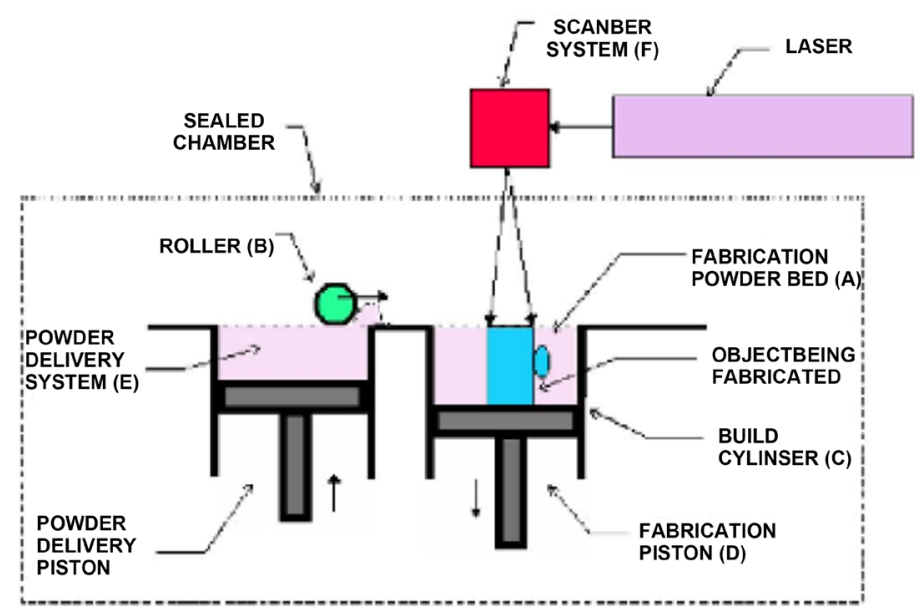

Figure 8. A schematic of the selective laser sintering process [21].



Figure 9. Illustration of EBM process.

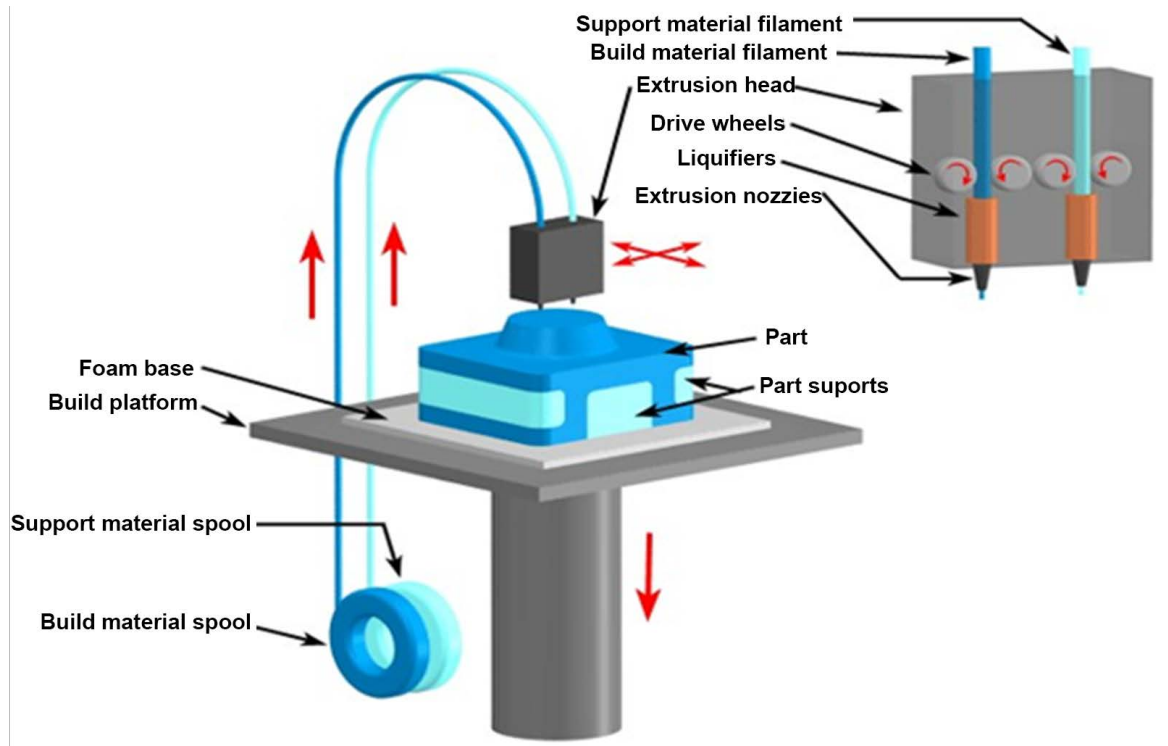

Figure 10. Illustration of extrusion deposition process. 
Table 1. Available state of the art and types of 3D Printers.

\begin{tabular}{ccc}
\hline Type & Technologies & Materials \\
\hline Extrusion & Fused deposition modeling (FDM) & $\begin{array}{c}\text { Thermoplastics (e.g. PLA, ABS), } \\
\text { eutectic metals, edible materials }\end{array}$ \\
& Direct metal laser sintering (DMLS) & Almost any metal alloy \\
& Electron beam melting (EBM) & Titanium alloys \\
Granular & Selective heat sintering (SHS) & Thermoplastic powder \\
& Selective laser sintering (SLS) & Thermoplastics, metal powders, \\
& Powder bed and inkjet head 3d & ceramic powders \\
& printing, Plaster-based 3D & printing (PP) \\
Laminated & Laminated Object Manufacturing \\
& (LOM) & Paper, metal foil, plastic film \\
Light polymerized & Stereolithography (SLA) & Photopolymer \\
& Digital Light Processing (DLP) & Liquid resin \\
\hline
\end{tabular}

its melting point so that it flows easily through the nozzle and forms the layer. The plastic hardens immediately after flowing from the nozzle and bonds to the layer below. Once a layer is built, the platform lowers, and the extrusion nozzle deposits another layer. The layer thickness and vertical dimensional accuracy is determined by the extruder die diameter, which ranges from 0.13 to $0.33 \mathrm{~mm}$. In the X-Y plane, $0.0254 \mathrm{~mm}$ resolution is achievable. Range of materials available includes the ABS, polyamide, polycarbonate, polyethylene, polypropylene, and investment casting wax.

\section{1) Software}

Different software available online can be adopted to slice the CAD file based on the geometrically defined object with the CAD/CAM software. The most important aspect of the software is the ability to convert the CAD file into G-code for positional movement of the nozzle head and for "slicing" in 3D printing. G-code is a CNC based machine tool language that is adopted to describe the toolpath and the functions of the tool itself during the fabrication of $3 \mathrm{D}$ objects. It is a script-based language, where each line usually conveys one type of machine movement or machine setting [26]. Few G-codes controllers are available for free online. One of them adopted in this research is the RepetierHost controller.

\section{2) Repetier-Host}

With this software, the user can add multiple files to a virtual print bed and at the same time size, and slice the CAD object using the built-in software for slicing. Repetier-Host is programmed in C\# and it is cross-platform across Windows, Mac and Linux. The screen shot is as shown in Figure 11. The RepetierHost is an Open-GL dependency, that is adopted for the rendering of the print bed [27]. 


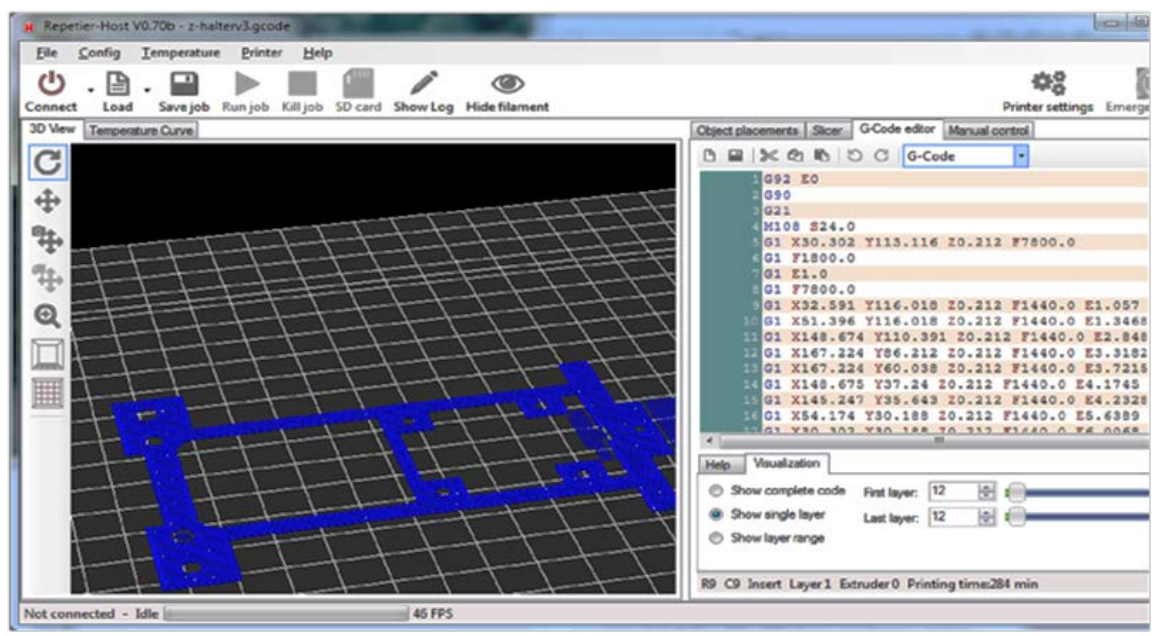

Figure 11. Screen shot of Repetier Host Software.

\section{3) Designing Using CAD}

Computer Aided Design CAD is the use of computer systems to create, modify, analyze, or optimize designs [28]. This software is adopted to increase the productivity of the designer, improve the quality of designs, improve communications through documentation, and to create a database for manufacturing. CAD output is usually in the form of electronic files used for 3D printing, machining, or other manufacturing operations. After completion of the 3D design with CAD software, they are converted into a STL file format.

\section{4) Conversion to STL File Format}

An STL file is a triangular representation of a 3D surface geometry. The surface is tessellated logically into a set of oriented triangles (facets). Each facet is described by the unit outward normal and three points listed in counter clockwise order representing the vertices of the triangle [29]. Most recent commercial CAD/CAM software systems are capable of generating STL files directly from a surface model [30]. The choice of the tolerance is strongly dependent on the target application of the produced STL file.

\section{Our Efforts to Date in Nigeria}

It is interesting to note that since the introduction of AM technology globally (more than 30 years ago), very few Universities and Institutes in Nigeria are currently researching and using the technology. The known ones include the Prototype Engineering Development Ilesa (PEDI), Edo University Iyamho (EUI) in collaboration with Federal University of Petroleum Resources, Effurun (FUPRE), Ahmadu Bello University Zaria, Federal University Oye Ekiti, Afe Babalola University Ado Ekiti (ABUAD), ELIZADE University Ilara Mokin, General Electric (GE) launched the "Lagos Garage," a new advanced manufacturing program in Lagos, Nigeria, University of Ibadan, and National Agency for Science and Engineering Infrastructure (NASENI), Nigeria are gradually developing the FDM technology. 
However, lack of experts in the AM technology tends to slow down the development in Nigeria, it is believed that with more established training and adequate funding from governmental agencies, industries, NGO's and research institutes could spur rapid growth in the development of the technology.

\subsection{Edo University Iyamho and ABUAD's Development Effort}

A research into the development of a 3D printer from local materials was conducted at the Department of Mechanical/Mechatronics Engineering, Edo University Iyamho and Afe Babalola University Ado Ekiti (ABUAD). At the onset, the project was divided into four phases (i.e. research, design, development and analysis phase). Figure 12 shows the block diagram for the development procedure and the implementation strategy. FUPRE is supporting with CAD/CAM technical faculty domiciled in Mechanical engineering department, by using locally sources materials for $3 \mathrm{D}$ printing research endeavours.

The development of the system can be categorized into three main parts i.e. mechanical, hardware and simulations, and software part (Repetier Host).

\section{Mechanical Part Design}

The body kit shown in Figure 13 is used to provide support for the system and protect the electronic circuit from fluid that might cause the malfunctioning of the electronic circuit.

In general, the design of the $3 \mathrm{D}$ printer body kit was based on 1) functions to be performed, 2) internal component assembly for optimum performance and 3) minimum centre of gravity for the stability while in static condition. The body of the $3 \mathrm{D}$ printer is designed in such a way to accommodate the frame, $\mathrm{X}, \mathrm{Y}$, and $\mathrm{Z}$ axes shafts and bushings, X-carriage, Print plate, Electronics, Stepper motors, Stepper motor controllers and End stops.

\section{1) 3D Printer Design Chassis}

The 3D printer contains the frame, 5 stepper motors, print plate, extruder, etc. Figure 13 shows the design of 3D printer body kit using Autodesk Inventor 2016.

\section{2) Software Part (Repetier Host)}

Repetier Host software is employed to control the axes of the 3D printer and slicing of the STL CAD files. The interfaces shown in Figure 14 below represent the steps involved in setting up the Repetier Host software, connect the printer and choose the G-code file to be printed.

\subsection{Bill of Engineering Measurement and Evaluation}

The total estimates for this experimental work is about five hundred thousand naira ( $\$ 500,000.00)$ only. Some parts were locally sourced while others were imported. This is a demonstration that the $3 \mathrm{D}$ printer can be fabricated locally with nearly $80 \%$ sourced materials. This could create more jobs for our young graduates and the unemployed youth in Nigeria. 


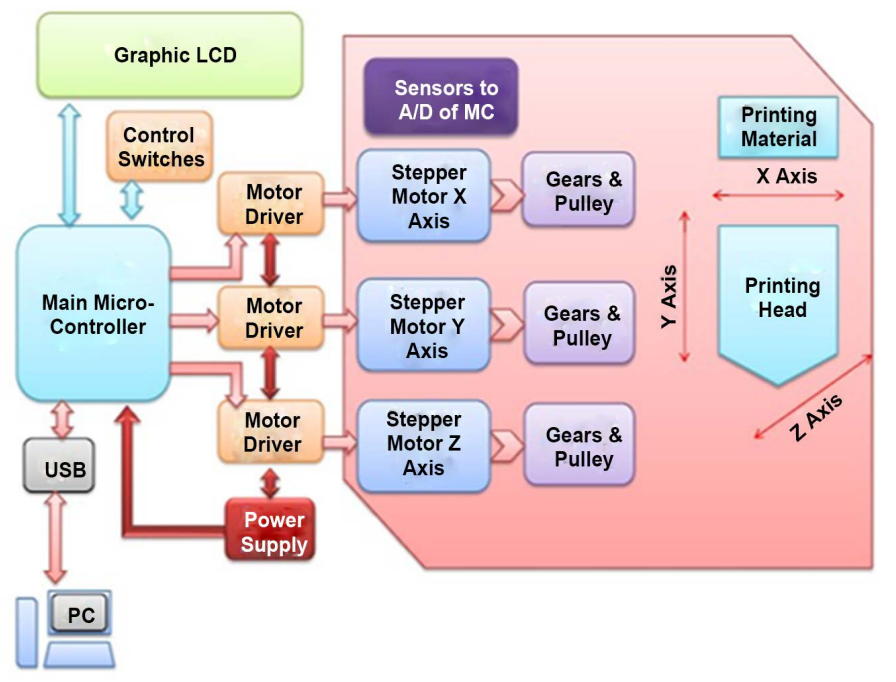

Figure 12. Block diagram of the developed 3D printer.
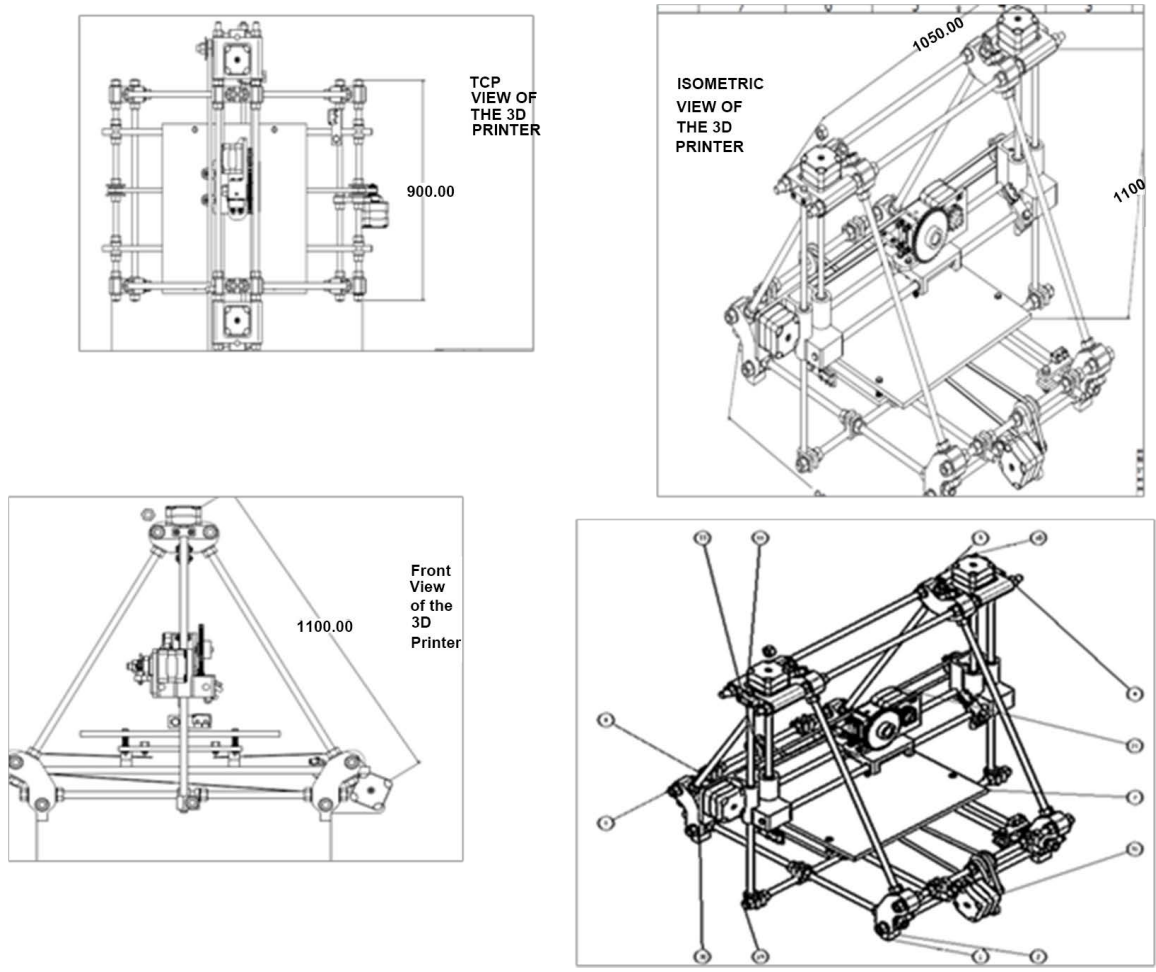

Figure 13. Design of 3D printer body kit using Autodesk Inventor 2016.

\section{Result and Discussion}

The result obtained from the design of the $3 \mathrm{D}$ printer using the integration of the aforementioned hardware components and software is shown in Figure 15(a) and Figure 15(b).

Figure 15 shows the snapshot of the 3D printer after necessary packaging has been done so as to make it more presentable. The packaging was done to protect the electronic parts of the printer that could otherwise be damaged when exposed to fluid. 




Figure 14. Illustration of the configuration of repetier host software.

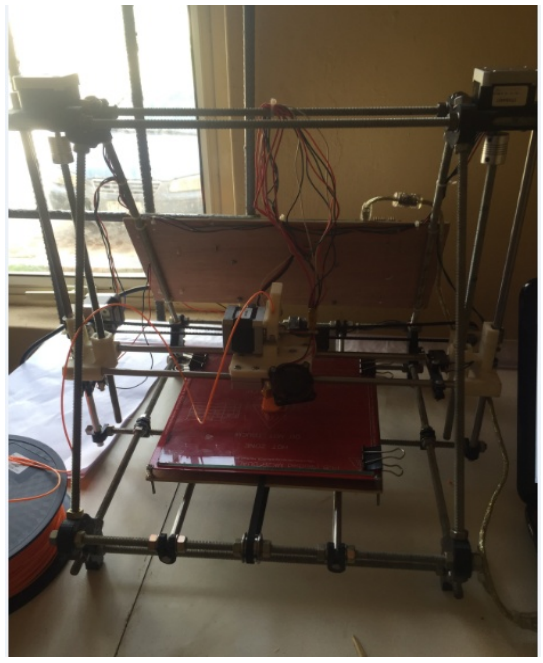

(a)

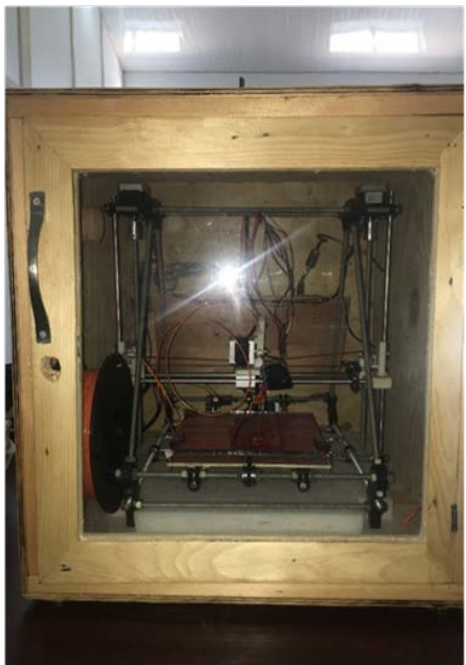

(b)

Figure 15. (a) Illustration of the developed 3D Printer; (b) Finished 3D Printer.

The flow nozzle comes in various sizes. The flow rate of the molten material (off the nozzle) is inversely proportional to the diameter of the nozzle and the print quality of the finished part is also inversely proportional to the speed at which the robot prints. Therefore it is important to determine the trade-off between speed and print quality in order to obtain the optimum flow rate for the nozzle. It is noted that one cannot exceed the diameter of the nozzle and also this is not advisable. It is deduced therefore that a user has the choice of a trade-off either by increasing the deposition speed in order to reduce the cycle time thereby affecting the surface quality of the print or improving the print 


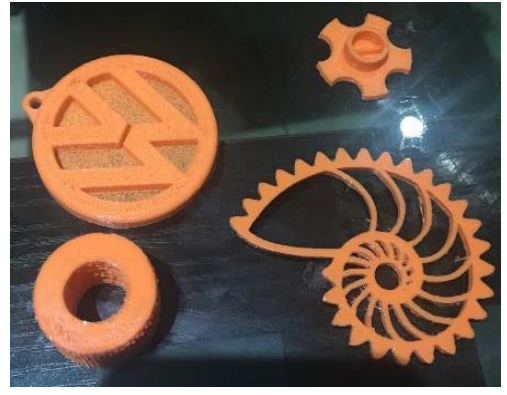

VW Logo, Nut and Nautilus gear



Motor mounts for fire extinguishing robot

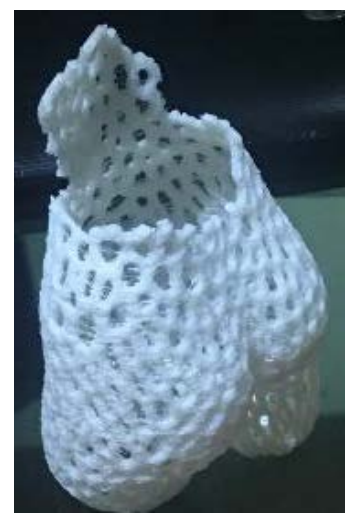

Lower shape of human body

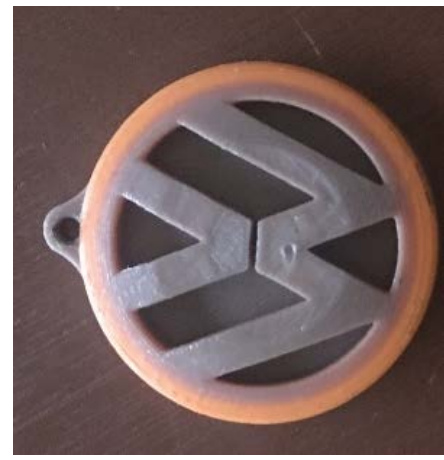

$0.1 \mathrm{~mm}$ quality of the VW logo

Figure 16. Samples of printed components.

quality with a lower deposition speed.

\section{Samples of Materials Printed}

The objects printed with the developed 3D Printer are as shown in Figure 16.

The quality of the objects depends on the print quality and the feed rate specified before slicing. If the print quality is $0.1 \mathrm{~mm}$ the printed object will be finer and stronger than a print quality of $0.2 \mathrm{~mm}$ because the extruder deposits the plastic at an interval of $0.1 \mathrm{~mm}$ making the printed object to be more compact therefore improving the surface quality.

\section{Conclusions}

This work demonstrated the development of a 3D printer from locally sourced materials. From this research, it is possible to practically demonstrate the fabrication of a 3D printer with locally sourced materials in Nigeria. This is a novel idea especially in Nigeria where it is one of the trial runs into the additive manufacturing technology. The following conclusions can be drawn from this work:

- This approach enhances hands-on practical experiences to be gained.

- The extensive use of microcontroller ensured the integration step to be simpler. It is important to modularise each section of the controller to allow for 
easy debugging at the integration step.

- The developed 3D printer successfully printed various components as shown in Figure 16 with a total budget of N500000.00.

- Also, because FDM 3D printing technology is a zero waste technology, it should be promoted in Nigeria to reduce environmental pollution. They are more sustainable than material removal manufacturing methods. Interestingly, more materials than ever before are gradually becoming available to fabricate parts and thereby reducing the occurrence of machine/process errors. Hence, RP and RM technologies have enormous potential to reshape modern manufacturing.

\section{Future Project Focus}

Research is ongoing (based on the performance of the fabricated machine) to ensure the following:

- The machine could be enhanced to use lead screw for the motion transmission mechanism on all the axes. This would improve the print accuracy of the printer.

- The mechanical and thermal properties of local thermoplastic materials can be improved. Local materials such as rubber, PVC pellets, ABS etc can be reinforced with coconut, periwinkle shells, etc., to enhance the toughness of the printed part.

- The machine could be improved to print different mix of materials in a single print operation.

The fabricated $3 \mathrm{D}$ printer is compared with existing $3 \mathrm{D}$ printers to judge the quality of the pieces produced.

\section{References}

[1] Page, T. (2011) Design for Additive Manufacturing.

[2] Bayley, C., et al. (2014) Understanding Error Generation in Fused Deposition Modeling. Proceedings of the ASPE Spring Topical Meeting on Dimensional Accuracy and Surface Finish in Additive Manufacturing, Berkeley, 13-16 April 2014.

[3] Levy, G.N., Schindel, R. and Kruth, J.-P. (2003) Rapid Manufacturing and Rapid Tooling with Layer Manufacturing (LM) Technologies, State of the Art and Future Perspectives. Cirp Annals-Manufacturing Technology, 52, 589-609. https://doi.org/10.1016/S0007-8506(07)60206-6

[4] Schmid, R. and Kalpakjian, S. (2006) Manufacturing Engineering and Technology. Pearson Prentice Hall, Upper Saddle River.

[5] Udroiu, R. and Ivan, N. (2008) Rapid-X Using 3D Printers. Supplement of Academic Journal of Manufacturing Engineering, 2, 199-205.

[6] Horvath, J. (2014) A Brief History of 3D Printing, in Mastering 3D Printing. Springer, 3-10. https://doi.org/10.1007/978-1-4842-0025-4_1

[7] Mironov, V., et al. (2003) Organ Printing: Computer-Aided Jet-Based 3D Tissue Engineering. TRENDS in Biotechnology, 21, 157-161.

https://doi.org/10.1016/S0167-7799(03)00033-7

[8] Bose, S., Vahabzadeh, S. and Bandyopadhyay, A. (2013) Bone Tissue Engineering 
Using 3D Printing. Materials Today, 16, 496-504.

https://doi.org/10.1016/j.mattod.2013.11.017

[9] Campbell, T., et al. (2011) Could 3D Printing Change the World. Technologies, Potential, and Implications of Additive Manufacturing, Atlantic Council, Washington DC.

[10] Kruth, J.P., Leu, M.C. and Nakagawa, T. (1998) Progress in Additive Manufacturing and Rapid Prototyping. CIRP Annals-Manufacturing Technology, 47, 525-540. https://doi.org/10.1016/S0007-8506(07)63240-5

[11] Wohlers, T. (2010) Additive Manufacturing State of the Industry. Wohlers Report.

[12] Schröder, M., Falk, B. and Schmitt, R. (2015) Evaluation of Cost Structures of Additive Manufacturing Processes Using a New Business Model. Procedia CIRP, 30, 311-316. https://doi.org/10.1016/j.procir.2015.02.144

[13] Statistics, N.B. (2009) Annual Abstract of Statistic. National Bureau of Statistics (NBS), Abuja.

[14] Statistics, N.B.O., GDP 2015 (2015) Formal and Informal Sector Estimated Split: Sectorial Report. In: Statistics, N.B.O., Ed., National Bureau of Statistics (NBS), Abuja.

[15] Post, M.J. (2014) Cultured Beef: Medical Technology to Produce Food. Journal of the Science of Food and Agriculture, 94, 1039-1041. https://doi.org/10.1002/jsfa.6474

[16] Post, M.J., Rahimi, N. and Caolo, V. (2013) Update on Vascularization in Tissue Engineering. Regenerative Medicine, 8, 759-770. https://doi.org/10.2217/rme.13.74

[17] Lucas, C. and Spiegel, M. (2015) 3D Printing Skin Grafts for Facial Reconstruction.

[18] Balogun, V.A., Kirkwood, N.D. and Mativenga, P.T. (2014) Direct Electrical Energy Demand in Fused Deposition Modelling. Procedia CIRP, 15, 38-43. https://doi.org/10.1016/j.procir.2014.06.029

[19] Balogun, V. and Oladapo, B. (2016) Electrical Energy Demand Modeling of 3D Printing Technology for Sustainable Manufacture. International Journal of Engineering, 29, 954-961.

[20] Balogun, V.A., Kirkwood, N. and Mativenga, P.T. (2015) Energy Consumption and Carbon Footprint Analysis of Fused Deposition Modelling: A Case Study of RP Stratasys Dimension SST FDM.

[21] Santos, E.C., et al. (2006) Rapid Manufacturing of Metal Components by Laser Forming. International Journal of Machine Tools and Manufacture, 46, 1459-1468. https://doi.org/10.1016/j.ijmachtools.2005.09.005

[22] Lan, H., et al. (2004) A Web-Based Manufacturing Service System for Rapid Product Development. Computers in Industry, 54, 51-67. https://doi.org/10.1016/j.compind.2003.07.006

[23] Yan, Y., et al. (2009) Rapid Prototyping and Manufacturing Technology: Principle, Representative Technics, Applications, and Development Trends. Tsinghua Science \& Technology, 14, 1-12. https://doi.org/10.1016/S1007-0214(09)70059-8

[24] Safari, A. (2001) Processing of Advanced Electroceramic Components by Fused Deposition Technique. Ferroelectrics, 263, 45-54. https://doi.org/10.1080/00150190108225177

[25] Cho, H., et al. (2000) Determining Optimal Parameters for Stereolithography Processes via Genetic Algorithm. Journal of Manufacturing Systems, 19, 18-27. https://doi.org/10.1016/S0278-6125(00)88887-1 
[26] Smid, P. (2007) CNC Programming Handbook. Industrial Press.

[27] Meding, M.U. (2016) Web-Based Model Slicing for 3D Printers. University of Massachusetts Lowell, Lowell.

[28] Boothroyd, G. (1994) Product Design for Manufacture and Assembly. Computer-Aided Design, 26, 505-520. https://doi.org/10.1016/0010-4485(94)90082-5

[29] Szilvśi-Nagy, M. and Matyasi, G. (2003) Analysis of STL Files. Mathematical and Computer Modelling, 38, 945-960. https://doi.org/10.1016/S0895-7177(03)90079-3

[30] Chen, Y., Ng, C. and Wang, Y. (1999) Generation of an STL File from 3D Measurement Data with User-Controlled Data Reduction. The International Journal of Advanced Manufacturing Technology, 15, 127-131.

https://doi.org/10.1007/s001700050049 